\title{
Nongenomic Glucocorticoid Suppression of a Postsynaptic Potassium Current via Emergent Autocrine Endocannabinoid Signaling in Hypothalamic Neuroendocrine Cells following Chronic Dehydration
}

\author{
Ning Wu, ${ }^{1}$ and ${ }^{-}$Jeffrey G. Tasker ${ }^{1,2}$
}

DOI:http://dx.doi.org/10.1523/ENEURO.0216-17.2017

${ }^{1}$ Department of Cell \& Molecular Biology, Tulane University, New Orleans, LA 70117 and ${ }^{2}$ Tulane Brain Institute, Tulane University, New Orleans, LA 70118

\section{Visual Abstract}

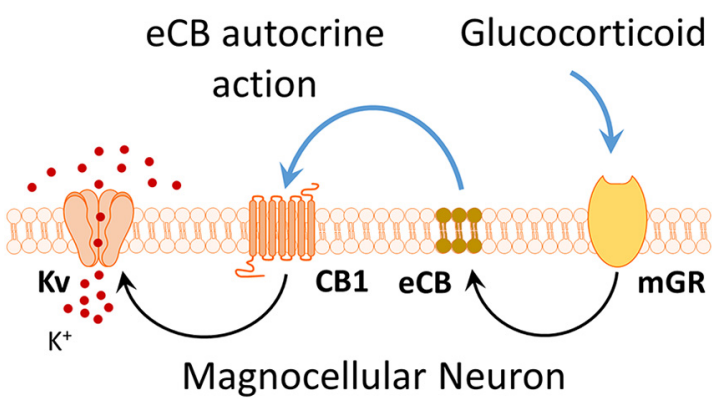

Glucocorticoids rapidly stimulate endocannabinoid synthesis and modulation of synaptic transmission in hypothalamic neuroendocrine cells via a nongenomic signaling mechanism. The endocannabinoid actions are synapse-constrained by astrocyte restriction of extracellular spatial domains. Exogenous cannabinoids have been shown to modulate postsynaptic potassium currents, including the A-type potassium current $\left(I_{A}\right)$, in different cell types. The activity of magnocellular neuroendocrine cells is shaped by a prominent $I_{A}$. We tested for a rapid glucocorticoid modulation of the postsynaptic $I_{\mathrm{K}}$ and $I_{\mathrm{A}}$ in magnocellular neuroendocrine cells of the hypothalamic paraventricular nucleus (PVN) using whole-cell recordings in rat brain slices. Application of the synthetic glucocorticoid dexamethasone (Dex) had no rapid effect on the $I_{\mathrm{K}}$ or $I_{\mathrm{A}}$ amplitude, voltage dependence, or kinetics in magnocellular neurons in slices from untreated rats. In magnocellular neurons from salt-loaded rats, however, Dex application caused a rapid suppression of the $I_{\mathrm{A}}$ and a depolarizing shift in $I_{\mathrm{A}}$ voltage dependence. Exogenously applied endocannabinoids mimicked the rapid Dex modulation of the $I_{A}$, and CB1 receptor antagonists and agonists blocked and occluded the Dex-induced changes in the $I_{\mathrm{A}}$, respectively, suggesting an endocannabinoid dependence of the rapid glucocorticoid effect. Preincubation of control slices in a gliotoxin resulted in the partial recapitulation of the glucocorticoid-induced rapid suppression of

\section{Significance Statement}

Stress causes elevated levels of glucocorticoid hormones and rapid and delayed glucocorticoid feedback effects in the brain. Glucocorticoids regulate synaptic inputs to hypothalamic neuroendocrine cells via a nongenomic release of endocannabinoid. We report a nongenomic glucocorticoid modulation of a postsynaptic A-type potassium current in magnocellular neurons via a novel autocrine endocannabinoid mechanism. The A-current modulation by glucocorticoids occurred in neurons from rats subjected to chronic dehydration via salt loading, but not in neurons from normally hydrated rats. Our findings suggest that chronic dehydration leads to glucocorticoid-induced endocannabinoid autocrine signaling in magnocellular neuroendocrine cells. The neuroplastic mechanisms for this emergent signaling may be related to neuronal-glial structural plasticity or to changes in rapid postsynaptic glucocorticoid and/or endocannabinoid actions. 
the $I_{\mathrm{A}}$. These findings demonstrate a glucocorticoid suppression of the postsynaptic $I_{\mathrm{A}}$ in PVN magnocellular neurons via an autocrine endocannabinoid-dependent mechanism following chronic dehydration, and suggest a possible role for astrocytes in the control of the autocrine endocannabinoid actions.

Key words: corticosteroid; HPA; magnocellular; oxytocin; stress; vasopressin

\section{Introduction}

Osmotic challenge elicits a neuroendocrine stress response that results in an increase in the circulating level of glucocorticoids (Roberts et al., 2011). Stress levels of glucocorticoids cause endocannabinoid synthesis in paraventricular nucleus (PVN) magnocellular neuroendocrine cells (MNCs) and parvocellular neuroendocrine cells (Di et al., 2003, 2005a, 2009; Malcher-Lopes et al., 2006). Endocannabinoids are synthesized from lipid precursors in neuronal membranes and are released canonically as retrograde signals to regulate the presynaptic release of glutamate and GABA (Di Marzo, 2011). Endocannabinoid synthesis is elicited in magnocellular neuroendocrine cells of the hypothalamus by depolarization (Hirasawa et al., 2004; Di et al., 2005b) and in response to oxytocin (Oliet et al., 2007), as well as in response to rapid glucocorticoid actions (Di et al., 2003, 2005a). Glucocorticoid- and depolarization-induced retrograde endocannabinoid release from MNCs of the hypothalamic PVN and supraoptic nucleus (SON) causes a synapse-specific suppression of glutamate release at excitatory synapses (Tasker, 2006; Tasker et al., 2006). Restriction of the retrograde endocannabinoid actions to glutamate synapses is controlled by astrocytes, since salt loading-induced neuronal-glial plasticity and pharmacologic inhibition of glial cell metabolism lead to spillover actions of endocannabinoids at neighboring GABA synapses (Di et al., 2013).

While endocannabinoids have been identified predominantly as retrograde messengers that regulate presynaptic neurotransmitter release, exogenous cannabinoids also have been reported to modulate postsynaptic potassium channels (Deadwyler et al., 1995; Mackie et al., 1995; Schweitzer, 2000). Glucocorticoids also have been shown to rapidly regulate postsynaptic properties by inhibiting potassium currents in PVN neurons (Zaki and Barrett-Jolley, 2002) and hippocampal neurons (ffrench-

Received June 21, 2017; accepted August 22, 2017; First published September 05, 2017.

The authors report no competing financial interests.

Author contributions: J.G.T. designed research; N.W. performed research; N.W. analyzed data; N.W. and J.G.T. wrote the paper

This work was supported by Department of Health and Human Services (HHS)/National Institutes of Health $(\mathrm{NIH}) /$ National Institute of Neurological Disorders and Stroke Grant NS042081, HHS/NIH/National Institute of Mental Health Grant MH066958, the Catherine and Hunter Pierson Chair in Neuroscience, and the Tulane Research Bridge Fund.

Acknowledgments: We thank Dr. Katalin Smith for her expert technical assistance.

Correspondence should be addressed to Jeffrey G. Tasker, Department of Cell \& Molecular Biology, Tulane University, 6400 Freret Street, New Orleans, LA 70117. E-mail: tasker@tulane.edu.

DOI:http://dx.doi.org/10.1523/ENEURO.0216-17.2017

Copyright (C) 2017 Wu and Tasker

This is an open-access article distributed under the terms of the Creative Commons Attribution 4.0 International license, which permits unrestricted use, distribution and reproduction in any medium provided that the original work is properly attributed.
Mullen, 1995; Olijslagers et al., 2008) and by modulating calcium-dependent potassium channels in pituitary $\mathrm{GH} 3$ and AtT-20 cells (Huang et al., 2006). The mechanisms of these postsynaptic actions of glucocorticoids have not been characterized.

The A-type potassium current $\left(I_{A}\right)$ is a prominent voltage-gated conductance in PVN magnocellular neurons that influences magnocellular neuron firing properties (Luther and Tasker, 2000; Ellis et al., 2007). Water deprivation or chronic salt loading induces dramatic structural and functional plasticity among magnocellular neuroendocrine cells and astrocytes of the hypothalamic PVN and supraoptic nucleus (Tasker et al., 2017). This plasticity results in functional changes in magnocellular neuron electrical activity that lead generally to an increase in excitability (Tasker et al., 2002). Here, we investigated whether glucocorticoids rapidly modulate the $I_{\mathrm{K}}$ and $I_{\mathrm{A}}$ of magnocellular neurons in a transcription-independent fashion via autocrine endocannabinoid signaling, and whether the rapid glucocorticoid modulation of the $I_{\mathrm{K}}$ and $I_{A}$ is altered with chronic osmotic stress via salt loading.

\section{Materials and Methods}

\section{Animals}

Male Sprague Dawley rats (5-6 weeks old; Harlan Laboratories) were used with the approval of the Tulane University Animal Care and Use Committee and in accordance with US Public Health Service guidelines. Rats were dehydrated via chronic salt loading by restricting them to drinking water with $2 \% \mathrm{NaCl}$ for $6-8 \mathrm{~d}$. Untreated control rats were age matched and were provided with regular tap drinking water.

\section{Hypothalamic slice preparation}

Rats were decapitated with a rodent guillotine under deep halothane anesthesia. The brain was quickly removed and placed into ice-cold artificial CSF (aCSF) containing the following (in mM): $140 \mathrm{NaCl}, 3 \mathrm{KCl}, 1.3 \mathrm{MgSO}_{4}$, $1.4 \mathrm{NaH}_{2} \mathrm{PO}_{4}, 2.4 \mathrm{CaCl}_{2}, 11$ glucose, and 5 HEPES, with $\mathrm{pH}$ adjusted to 7.2-7.3 with $\mathrm{NaOH}$, the osmolarity was 290-300 mOsm, and the aCSF was bubbled with 100\% $\mathrm{O}_{2}$. The hypothalamus was blocked and the caudal surface of the tissue block was glued to the chuck of a vibrating tissue slicer. Two coronal hypothalamic slices $300 \mu \mathrm{m}$ in thickness and containing the PVN were sectioned, bisected at the midline, and submerged in a holding chamber in oxygenated aCSF at room temperature, where they were allowed to equilibrate for $>1.5 \mathrm{~h}$ before being transferred to a recording chamber.

\section{Electrophysiology}

Patch pipettes were pulled from borosilicate glass with a Flaming/Brown P-97 micropipette puller (Sutter Instruments) to a tip resistance of 3-4 M $\Omega$. They were filled with a solution containing the following (in $\mathrm{mm}$ ): 120 
K-gluconate, $10 \mathrm{KCl}, 1 \mathrm{NaCl}, 1 \mathrm{MgCl}_{2}, 1 \mathrm{EGTA}, 2 \mathrm{Mg}$-ATP, $0.3 \mathrm{Na}-\mathrm{GTP}$, and $10 \mathrm{HEPES}$; the $\mathrm{pH}$ was adjusted to 7.2 with $\mathrm{KOH}$, and the osmolarity was adjusted to $300 \mathrm{mOsm}$ with $20 \mathrm{~mm}$ D-sorbitol. For recordings, single hemi-slices were transferred from the holding chamber to a submersion recording chamber, where they were perfused with oxygenated aCSF at a rate of $2 \mathrm{ml} / \mathrm{min}$ and allowed to equilibrate for at least $15 \mathrm{~min}$ before starting the recordings. PVN neurons were visualized on a video monitor with a cooled CCD camera using infrared illumination and differential interference contrast optics, and were patch clamped under visual control. After achieving the wholecell configuration, the series resistance was compensated by $\geq 60 \%$ and the series resistance and whole-cell capacitance were continuously monitored during experiments. Magnocellular neurons in the PVN were identified based on their location, size, morphology, and electrophysiological properties (i.e., prominent $I_{\mathrm{A}}$ in voltage clamp and transient outward rectification in current clamp; Tasker and Dudek, 1991; Luther and Tasker, 2000). Recordings were performed using a Multiclamp 700A amplifier (Molecular Devices). Data were low-pass filtered at $2 \mathrm{kHz}$ with the amplifier and sampled at $10 \mathrm{kHz}$ using the pClamp 9 data acquisition and analysis software package (Molecular Devices).

Before experiments, cells were tested in current-clamp mode and excluded from analyses if they did not meet the following criteria: action potential amplitudes $\geq 50 \mathrm{mV}$ from the threshold to the peak, an input resistance at resting potential of at least $500 \mathrm{M} \Omega$, a resting membrane potential negative to $-50 \mathrm{mV}$, and a characteristic transient outward rectification (Tasker and Dudek, 1991; Luther and Tasker, 2000). Slices were then bathed in aCSF with tetrodotoxin (TTX; $1 \mu \mathrm{M})$ and $\mathrm{CdCl}_{2}(200 \mu \mathrm{M})$ to block voltage-gated sodium channels and calcium channels, respectively, and the recording configuration was switched to voltage clamp. The liquid junction potential (calculated at $15 \mathrm{mV}$ ) was corrected post hoc during data analysis. All voltage-clamp recordings were leak subtracted using a P/4 protocol. Series resistance compensation of $\geq 60 \%$ was routinely applied, and changes in series resistance were monitored and compensated for throughout the experiments. The series resistance at the beginning of recordings was $<20 \mathrm{M} \Omega$, and recordings were discarded if changes in series resistance of $>20 \%$ occurred during the recordings.

\section{Voltage dependence of activation and inactivation of the $I_{\mathrm{A}}$ and $I_{\mathrm{K}}$}

We used two separate voltage protocols to isolate the $I_{\mathrm{A}}$ in PVN magnocellular neurons (Fig. 1A). The first protocol included a $200 \mathrm{~ms}$ hyperpolarizing conditioning step to $-115 \mathrm{mV}$, which removed the inactivation of the $I_{\mathrm{A}}$, followed by sequential $200 \mathrm{~ms}$ depolarizing test pulses to between -75 and $+35 \mathrm{mV}$ in $10 \mathrm{mV}$ increments, which resulted in the activation of both the $I_{\mathrm{A}}$ and high voltageactivated potassium current $\left(I_{K}\right)$. The second protocol consisted of the same series of test pulses, but from a 200 ms depolarizing conditioning step to $-45 \mathrm{mV}$. The $I_{\mathrm{K}}$ was isolated from the $I_{\mathrm{A}}$ in the second protocol because the $I_{\mathrm{A}}$ in PVN magnocellular neurons is inactivated at $-45 \mathrm{mV}$ (Luther and Tasker, 2000). The $I_{A}$ was isolated by digitally subtracting the current responses generated by the second protocol from those generated by the first protocol, which removed the $I_{\mathrm{K}}$, leak current, and capacitive currents. The inactivation of the $I_{\mathrm{A}}$ was then studied with a third voltage protocol, consisting of sequential $200 \mathrm{~ms}$ conditioning steps to between -135 and $-25 \mathrm{mV}$ in 10 $\mathrm{mV}$ increments, which removed a variable amount of inactivation of $I_{\mathrm{A}}$, followed by a command step to $-15 \mathrm{mV}$. We introduced a small step, to $-75 \mathrm{mV}$ for $5 \mathrm{~ms}$, between the conditioning steps and the test steps in both protocols, which allowed all test steps to be delivered from the same initial voltage level. This way the voltage-clamp artifact was the same size and pulses were all more conveniently subtracted from each other or compared. We tested the effect of this short pretest step on $I_{A}$ and did not observe it to change $I_{A}$ significantly, since very little $I_{A}$ was activated at -75 and $5 \mathrm{~ms}$ was not sufficient to inactivate $I_{\mathrm{A}}$ (Luther and Tasker, 2000).

\section{Drug application}

Water-soluble forms of the steroids dexamethasone (Dex; dexamethasone-cyclodextrin complex, $1 \mu \mathrm{M}$ ) and corticosterone (corticosterone, 2-hydroxypropyl- $\beta$ cyclodextrin, $1 \mu \mathrm{M}$; Sigma-Aldrich) were directly dissolved in aCSF to their final concentrations and applied in the bath perfusion. The Dex-bovine serum albumin (BSA) conjugate $(10 \mu \mathrm{M})$ was dissolved in aCSF with $25 \% \beta$-cyclodextrin (Sigma-Aldrich) as a carrier to increase its solubility. The concentration of Dex-BSA (10 $\mu \mathrm{M})$ was selected to obtain an effective concentration of Dex of $\sim 1$ $\mu \mathrm{M}$, as the BSA conjugate had a steroid-to-BSA ratio of 8:1. TTX (1 $\mu \mathrm{M}$; Sigma-Aldrich) and $\mathrm{CdCl}_{2}(200 \mu \mathrm{M}$; SigmaAldrich) were dissolved in sterile water and stored in 10 $\mathrm{mm}$ stock solutions at $-20^{\circ} \mathrm{C}$, and were dissolved to their final concentrations in aCSF immediately before bath application. The endogenous cannabinoids anandamide (AEA) and 2-arachidonoylglycerol (2-AG; Tocris Bioscience) were dissolved in DMSO, stored in $10 \mathrm{~mm}$ stock solutions at $-20^{\circ} \mathrm{C}$, and dissolved to their final concentrations in aCSF just before their application in the bath. The cannabinoid receptor inverse agonists $\mathrm{N}$-(piperidin1-yl)-5-(4-iodophenyl)-1-(2,4-dichlorophenyl)-4-methyl$1 \mathrm{H}$-pyrazole-3-carboxamide (AM251; $1 \mu \mathrm{M}$; Tocris Bioscience) and rimonobant (SR141716, $1 \mu \mathrm{M}$; provided by the National Institute of Mental Health Chemical Synthesis and Drug Supply Program) were stored as $10 \mathrm{~mm}$ stock solutions in DMSO at $-20^{\circ} \mathrm{C}$ and dissolved to their final concentrations in aCSF before bath application. The vanilloid receptor agonist capsaicin and the antagonist capsazepine (Tocris Bioscience) were stored as $10 \mathrm{~mm}$ stock solutions in DMSO at $-20^{\circ} \mathrm{C}$ and dissolved to their final concentrations in aCSF before bath application. The protein synthesis inhibitor cycloheximide (CHX; Tocris Bioscience) was dissolved in sterile water and stored in a $10 \mathrm{~mm}$ stock solution at $-20^{\circ} \mathrm{C}$. Fluorocitrate (D, Lfluorocitric acid, barium salt; $100 \mu \mathrm{m}$; Sigma-Aldrich) was dissolved in aCSF with 15 min of sonication. The DMSO 

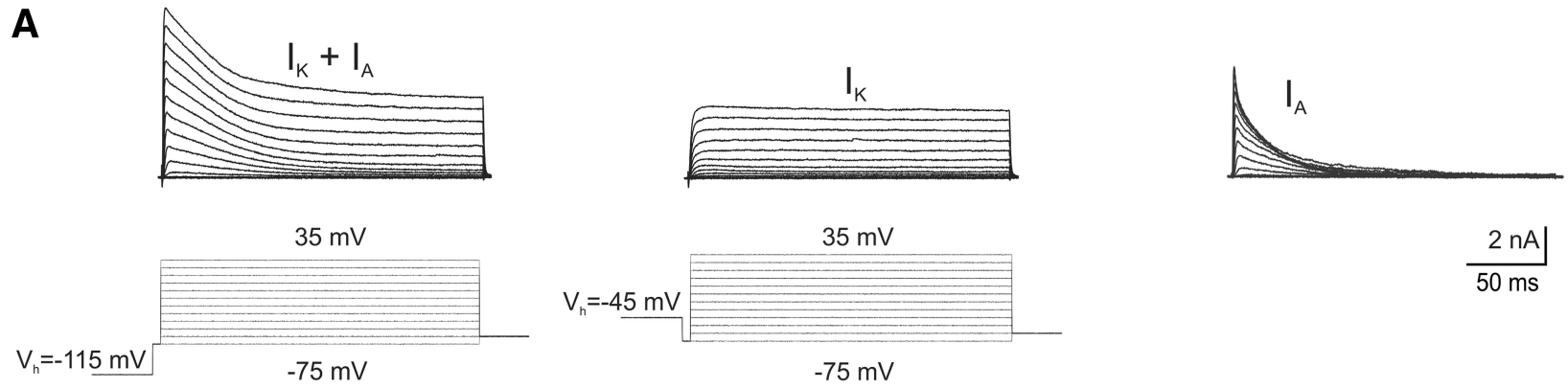

$\frac{2 \mathrm{nA}}{50 \mathrm{~ms}}$

B
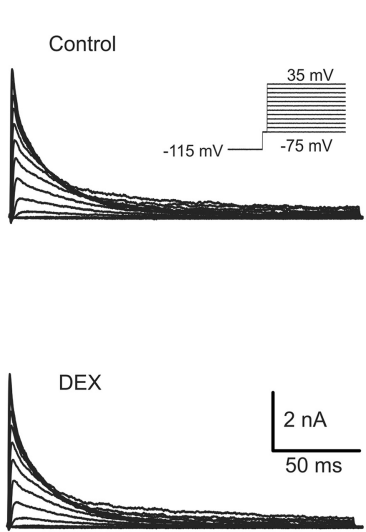

C

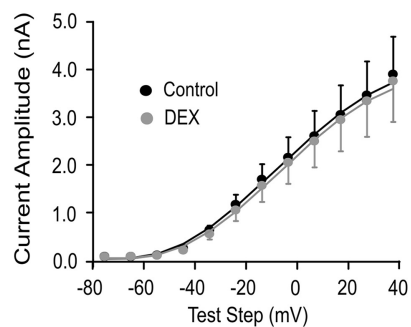

D

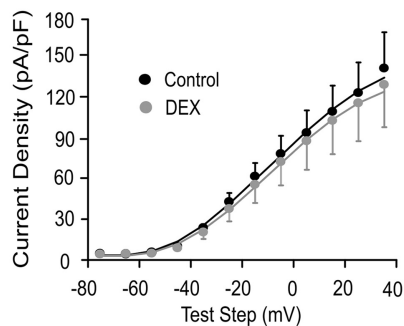

E

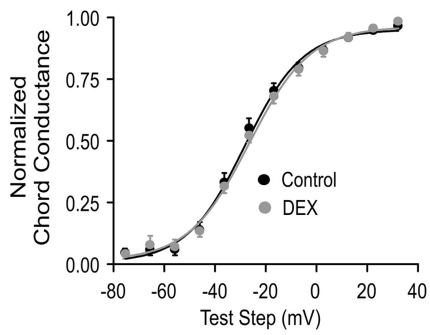

F

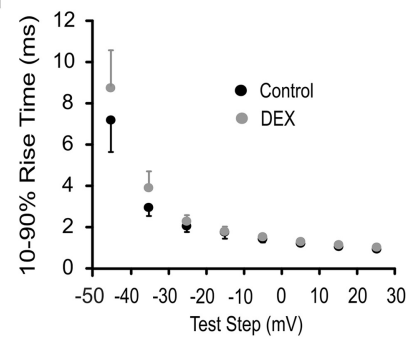

G

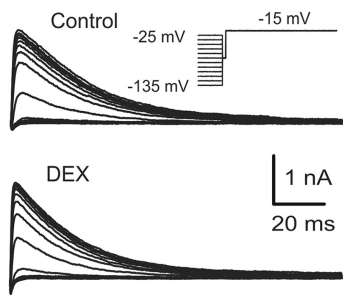

H

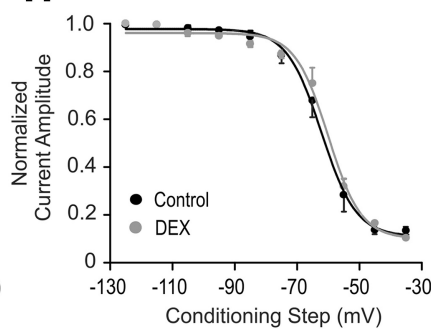

Figure 1. Dexamethasone had no rapid effect on $I_{\mathrm{A}}$ activation and inactivation in magnocellular neurons from untreated rats. $\boldsymbol{A}$, Voltage-clamp protocol for isolating $I_{\mathrm{K}}$ and $I_{\mathrm{A}}$. Combined $I_{\mathrm{K}}$ and $I_{\mathrm{A}}$ currents were evoked by stepping from a holding potential $\left(V_{\mathrm{h}}\right)$ of $-115 \mathrm{mV}$ to test steps of -75 to $35 \mathrm{mV}$ in $10 \mathrm{mV}$ increments (left: voltage steps below, current responses above). $I_{\mathrm{K}}$ was evoked by the same stepping protocol, except from a $V_{\mathrm{h}}$ of $-45 \mathrm{mV}$ (middle: voltage steps below, current responses above). Subtraction of the currents activated from a $V_{\mathrm{h}}$ of $-45 \mathrm{mV}$ from those activated from a $V_{\mathrm{h}}$ of $-115 \mathrm{mV}$ yielded the isolated low voltage-activated $I_{\mathrm{A}}$ (right current traces). $\boldsymbol{B}$, Representative traces showing voltage-dependent activation of $I_{\mathrm{A}}$ in PVN magnocellular neurons from untreated rats before and at the end of a $10 \mathrm{~min}$ Dex application $(1 \mu \mathrm{M})$. Inset, Activation voltage-clamp protocol. $\boldsymbol{C}$, Plots of the mean current amplitude of the $I_{A}$ vs the test step potential, showing no effect of Dex on the $I_{A}$ current amplitude. $\boldsymbol{D}$, Plots of the mean current density of the $I_{\mathrm{A}}$ (peak $I_{\mathrm{A}}$ /capacitance) vs the test step potential, showing no effect of Dex on the $I_{\mathrm{A}}$ current density. $\boldsymbol{E}$, Plots of the normalized chord conductance of the $I_{\mathrm{A}}$ vs the test step potential, showing no effect of Dex on the voltage dependence of activation of the $I_{\mathrm{A}}$. $\boldsymbol{F}$. Plots of the mean $I_{\mathrm{A}} 10-90 \%$ rise time vs test step potential; the Dex effect on the activation rate of $I_{\mathrm{A}}$ was not significant. $G$, Representative traces showing voltage-dependent inactivation of $I_{\mathrm{A}}$ in response to voltage steps to $-15 \mathrm{mV}$ from $200 \mathrm{~ms}$ conditioning steps between -135 and $-25 \mathrm{mV}$ before and after $10 \mathrm{~min}$ of Dex application (1 $\mu \mathrm{m})$. Dexamethasone had no effect on the inactivation voltage dependence of the $I_{\mathrm{A}}$. Inset, Inactivation voltage-clamp protocol. $\boldsymbol{H}$, Plots of the mean normalized current amplitude vs the conditioning step potential, showing no effect of DEX on the voltage dependence of $I_{\mathrm{A}}$ inactivation. All recordings were in PVN magnocellular neurons in slices from untreated rats.

and $\beta$-cyclodextrin vehicles without the cannabinoids or glucocorticoids had no effect on the wave form of the $I_{A}$.

\section{Statistical methods and curve fitting}

Values are expressed as the mean \pm SEM. Statistical analyses were performed using a two-way ANOVA with the Bonferroni multiple comparisons test for betweengroup comparisons and the Student's paired $t$ test for within-cell comparisons. Differences were considered significant at $p<0.05$. Boltzmann and exponential fits were used to fit data plots and current traces using the fitting methods provided in the GraphPad Prism software (GraphPad Software) and Clampfit 9 (pCLAMP 9, Molecular Devices), respectively.

\section{Results}

\section{Rapid glucocorticoid modulation of $I_{\mathrm{A}}$}

Corticosteroids rapidly modulate postsynaptic voltagegated potassium currents in hippocampal pyramidal neurons (Olijslagers et al., 2008). Magnocellular neuroendocrine cells of the hypothalamic PVN generate a prominent $I_{\mathrm{A}}$ that shapes their pattern of action potential firing (Luther and Tasker, 2000; Ellis et al., 2007). We first tested for a rapid effect of glucocorticoids on the activation and inactivation of the $I_{\mathrm{A}}$ in magnocellular neurons. The passive properties of the recorded magnocellular neurons are presented in Table 1. The synthetic glucocorticoid Dex, applied at a concentration determined in previous studies 
Table 1. Effects of chronic dehydration on passive electrical properties of magnocellular neurons

\begin{tabular}{lll}
\hline & $\begin{array}{l}\text { Untreated } \\
(n=9)\end{array}$ & $\begin{array}{l}\text { Dehydrated } \\
(n=15)\end{array}$ \\
Membrane capacitance $(\mathrm{pF})$ & $24.3 \pm 2.5$ & $40.0 \pm 4.4 *$ \\
Membrane resistance $(\mathrm{M} \Omega)$ & $794.3 \pm 48.4$ & $667.5 \pm 51.0 *$ \\
Holding current $(\mathrm{pA})$ & $17.7 \pm 3.8$ & $13.4 \pm 5.0 *$
\end{tabular}

$* p>0.05$ vs neurons from untreated rats, Student's unpaired $t$ test.

to be near saturating for rapid actions on synaptic transmission (1 $\mu \mathrm{M}$; Di et al., 2003, 2005a), had no effect on the $I_{\mathrm{A}}$. Based on a two-way ANOVA $(p>0.05, n=9)$, there was no change at the end of a $10 \mathrm{~min}$ bath application of Dex in the $I_{\mathrm{A}}$ mean current amplitude, the $I_{\mathrm{A}}$ current density, or the voltage dependence of $I_{\mathrm{A}}$ activation (Fig. $1 B-E)$. Dex also had no effect on the activation kinetics of the $I_{\mathrm{A}}(10-90 \%$ rise time measured with voltage steps from -115 to $-25 \mathrm{mV} ; p>0.05$, Student's paired $t$ test; Fig. $1 F$ ) or on the voltage dependence of $I_{\mathrm{A}}$ inactivation $(p>0.05$, two-way ANOVA; Fig. $1 G, H)$. The rate of inactivation was examined by fitting the $I_{\mathrm{A}}$ decay phase with a single exponential function to determine the inactivation time constant, which was also unchanged by Dex treatment (data not shown; $p>0.05$, Student's paired $t$ test). Dex had no effect on the amplitude, current density, or voltage dependence of the activation of the $I_{\mathrm{K}}(p>0.05$, ANOVA; data not shown).

Chronic dehydration causes loss of glial coverage; enhanced glutamatergic, GABAergic, and noradrenergic synaptic regulation of magnocellular neurons; and altered voltage-gated currents (Tasker et al., 2017). We next tested the possibility that glucocorticoid modulation of the $I_{A}$ in PVN magnocellular neurons is altered under conditions of chronic dehydration caused by salt loading. Five to 7 days of salt loading caused an increase in the membrane capacitance and a decrease in the input resistance of magnocellular neurons (Table 1), which are characteristic of dehydration-induced hypertrophy in the magnocellular neurons (Miyata and Hatton, 2002; Di and Tasker, 2004; Shah et al., 2014). Unlike neurons from untreated rats, bath application of Dex $(1 \mu \mathrm{M})$ to PVN magnocellular neurons $(n=15)$ in slices from salt-loaded rats caused decreases in both the $I_{\mathrm{A}}$ current amplitude and the $I_{\mathrm{A}}$ current density $(p<0.05$, two-way ANOVA followed by the Bonferroni multiple comparisons test for each test step; Fig. $2 A-C)$ and shifted the activation curve of $I_{\mathrm{A}}$ positive by $4.9 \mathrm{mV}(p<0.01$; Student's paired $t$ test; Fig. $2 D$ ) within $10 \mathrm{~min}$. The $I_{\mathrm{A}} 10-90 \%$ rise time (Fig. $2 E$ ) and the voltage dependence of $I_{A}$ inactivation (Fig. $2 F, G$ ) were unchanged. Like magnocellular neurons from untreated rats, Dex had no effect on the amplitude, current density, or voltage dependence of activation of the $I_{\mathrm{K}}$ in magnocellular neurons recorded in slices from salt-loaded rats (data not shown).

The endogenous glucocorticoid corticosterone had a similar effect on the $I_{\mathrm{A}}$ activation in MNCs from dehydrated rats. A $10 \mathrm{~min}$ bath application of corticosterone (1 $\mu \mathrm{M})$ reduced the $I_{\mathrm{A}}$ mean current amplitude $(p<0.01$,
A
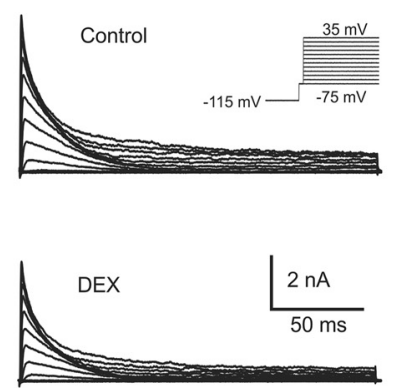

B

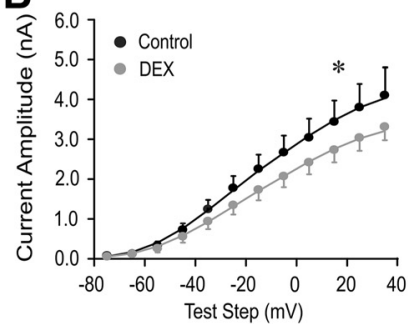

C

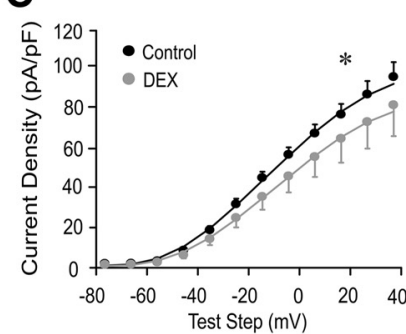

D
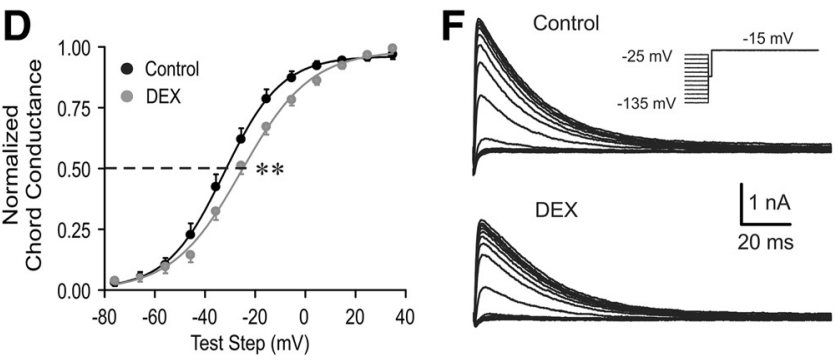

E

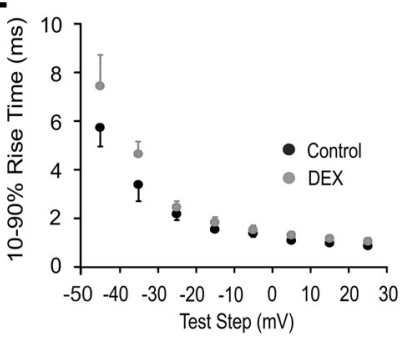

G

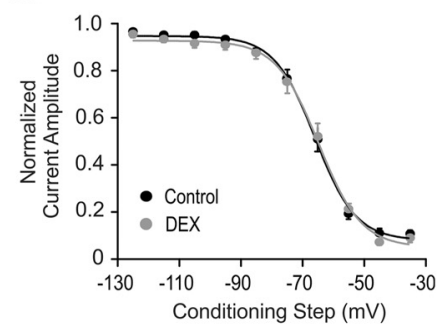

Figure 2. Rapid glucocorticoid modulation of $I_{A}$ in PVN magnocellular neurons from salt-loaded rats. $\boldsymbol{A}$, Representative traces showing voltage-dependent activation of $I_{A}$ in PVN magnocellular neurons from salt-loaded rats before and at the end of a 10 min Dex application $(1 \mu \mathrm{M})$. Inset, Activation voltage-clamp protocol. $\boldsymbol{B}$, Plots of the mean peak amplitude of the $I_{\mathrm{A}}$ vs the test step potential; Dex caused a significant reduction in the $I_{A}$ current amplitude. $\boldsymbol{C}$, Plots of the mean current density (peak current/capacitance) of the $I_{A}$ vs the test step potential; Dex caused a significant reduction in the $I_{A}$ current density. $\boldsymbol{D}$, Plots of the normalized chord conductance of the $I_{\mathrm{A}}$ vs the test step potential; Dex caused a significant shift to the right in the voltage dependence of activation of the $I_{\mathrm{A}}$. $\boldsymbol{E}$, Plots of the mean $10-90 \% I_{\mathrm{A}}$ rise time vs the test step potential; Dex did not change the $I_{\mathrm{A}}$ activation kinetics. $\boldsymbol{F}$, Representative traces showing voltage-dependent inactivation of $I_{\mathrm{A}}$ in response to voltage steps to $-15 \mathrm{mV}$ from 200 ms conditioning steps between -135 and $-25 \mathrm{mV}$ before and at the end of a $10 \mathrm{~min}$ Dex application $(1 \mu \mathrm{M})$. Inset, Inactivation voltage-clamp protocol. $\mathbf{G}$, Plots of the mean normalized current amplitude vs the conditioning potential. Dexamethasone had no effect on the voltage dependence of $I_{\mathrm{A}}$ inactivation. All recordings were in PVN magnocellular neurons in slices from salt-loaded rats. $* p<0.05 ; * * p<0.01$ with ANOVA. 
A
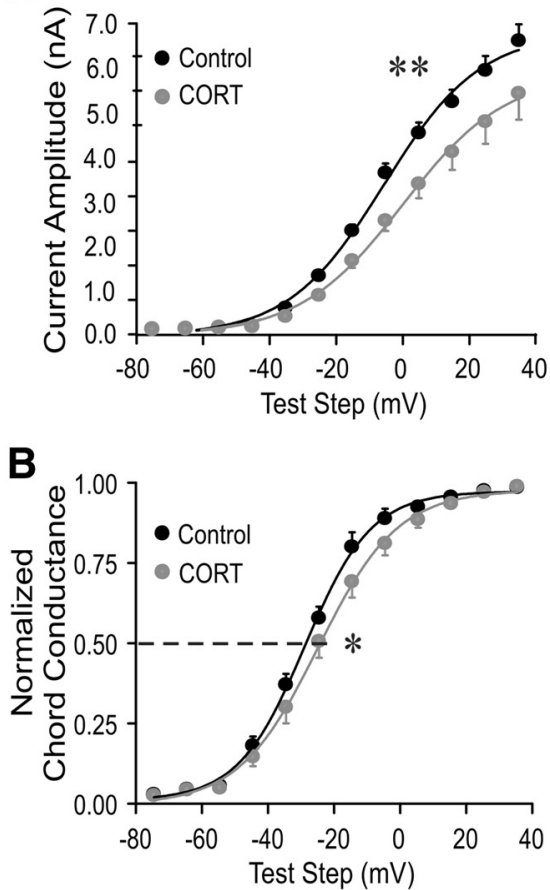

C

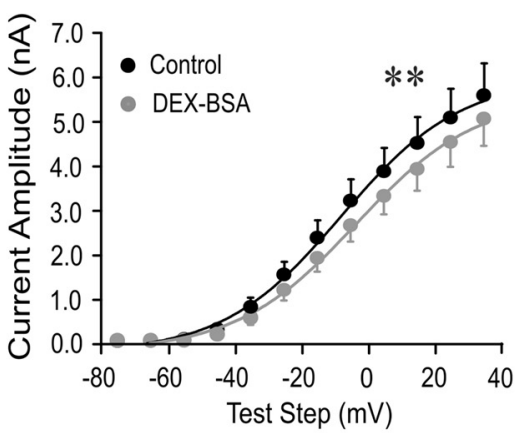

D

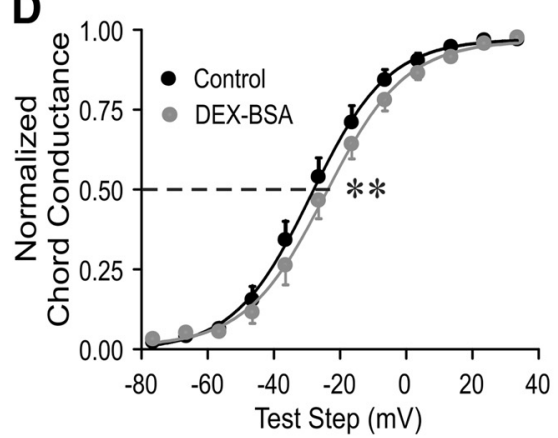

E

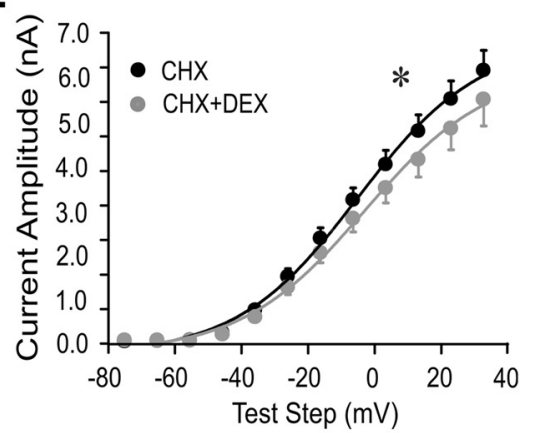

F

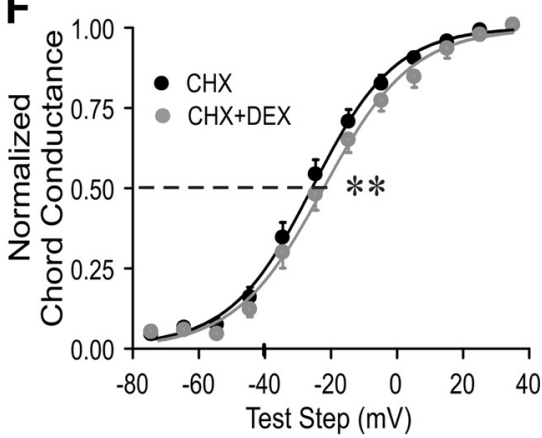

Figure 3. The rapid glucocorticoid effect on $I_{\mathrm{A}}$ in magnocellular neurons from salt-loaded rats was mediated by a membraneassociated receptor. $\boldsymbol{A}-\boldsymbol{F}$, Plots of the mean current amplitude of the $I_{\mathrm{A}}(\boldsymbol{A}, \boldsymbol{C}, \boldsymbol{E})$ and the $I_{\mathrm{A}}$ voltage dependence of activation (normalized chord conductance; $\boldsymbol{B}, \boldsymbol{D}, \boldsymbol{F}$ ) vs the test step potential before and at the end of a 10 min application of the endogenous glucocorticoid corticosterone (Cort), the membrane-impermeant glucocorticoid Dex-BSA, and Dex in the presence of the protein translation inhibitor $\mathrm{CHX}$. The endogenous glucocorticoid Cort $(\boldsymbol{A}, \boldsymbol{B})$, and the membrane-impermeant glucocorticoid Dex-BSA $(\boldsymbol{C}, \boldsymbol{D})$ reduced the $I_{\mathrm{A}}$ peak amplitude and shifted the $I_{\mathrm{A}}$ voltage dependence to the right. Blocking protein synthesis $(\boldsymbol{E}, \boldsymbol{F})$ failed to block the glucocorticoid modulation of the $I_{\mathrm{A}} \cdot * p<0.05 ; * * p<0.01$ with ANOVA in $\boldsymbol{A}, \boldsymbol{C}, \boldsymbol{E}$ and with Student's paired $t$ test in $\boldsymbol{B}, \boldsymbol{D}, \boldsymbol{F}$.

two-way ANOVA, Bonferroni's test; Fig. $3 A$ ) and induced a $4.3 \mathrm{mV}$ positive shift in the $I_{A}$ half-activation potential in MNCs from dehydrated rats $(n=10 ; p<0.05$, Student's paired $t$ test; Fig. $3 B$ ). Corticosterone had no effect on the voltage dependence of inactivation or on the inactivation time constant of $I_{\mathrm{A}}$ (data not shown).

Rapid glucocorticoid modulation of synaptic inputs to hypothalamic magnocellular and parvocellular neuroendocrine cells are mediated by a membrane-associated receptor (Di et al., 2003, 2005a). Here, we investigated whether the rapid glucocorticoid modulation of the $I_{\mathrm{A}}$ in PVN magnocellular neurons from dehydrated rats is also mediated by a membrane-associated glucocorticoid receptor. Bath application of the membrane-impermeant Dex-BSA conjugate $(10 \mu \mathrm{M})$, like Dex, reduced the mean current amplitude $(p<0.01$, two-way ANOVA followed by Bonferroni multiple comparisons test for each test step, $n=7$; Fig. $3 C$ ) and caused a $3.4 \mathrm{mV}$ positive shift in the $I_{\text {A }}$ half-activation potential $(n=7 ; p<0.01$, Student's paired $t$ test; Fig. 3D). This implicated a membrane site of steroid action. We used a 10-fold higher concentration of Dex-BSA because the Dex-to-BSA ratio of the Dex-BSA compound was 8:1, and we assumed that a single Dex molecule per Dex-BSA was available to bind to the receptor. The weaker effect of the Dex-BSA compared with Dex could be due to a lower effective concentration of available Dex to bind to the receptor or to a steric hindrance of Dex binding by the Dex-BSA three-dimensional structure. We have shown recently that free molecules of Dex do not dissociate from the Dex-BSA conjugate to penetrate into the cell (Weiss et al., in press).

To determine whether the rapid glucocorticoid effect on $I_{A}$ in MNCs from dehydrated rats is independent of de novo protein synthesis, we tested the sensitivity of the Dex effect to the protein synthesis inhibitor cycloheximide. Following a 30 min preincubation of slices in cycloheximide $(10 \mu \mathrm{M})$, the Dex-induced suppression of $I_{A}$ amplitude ( $p<0.05$, two-way ANOVA, Bonferroni's post hoc test; $n=7$; Fig. $3 E$ ) and positive shift in $I_{\mathrm{A}}$ halfactivation potential (by $3.2 \mathrm{mV} ; p<0.01$, Student's paired $t$ test; $n=7$; Fig. 3F) within 10 min were maintained. This indicated that the Dex effect on $I_{\mathrm{A}}$ does not require protein synthesis and is mediated by a nontranscriptional mechanism.

\section{Endocannabinoid dependence of the glucocorticoid modulation of the $I_{\mathrm{A}}$}

Rapid glucocorticoid modulation of glutamatergic synaptic inputs to magnocellular and parvocellular neuroendocrine cells of the hypothalamus are mediated by the retrograde release of an endocannabinoid (Di et al., 2003, 2005a). Here, we tested for the endocannabinoid dependence of the rapid glucocorticoid modulation of the postsynaptic $I_{\mathrm{A}}$ in PVN magnocellular neuroendocrine cells. Bath application of the endocannabinoid 2-AG (1 $\mu \mathrm{M})$ caused a decrease in the mean $I_{\mathrm{A}}$ peak amplitude $(p<$ 


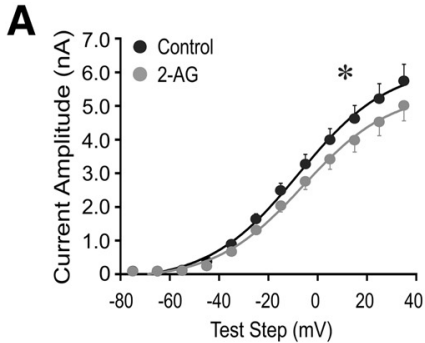

B

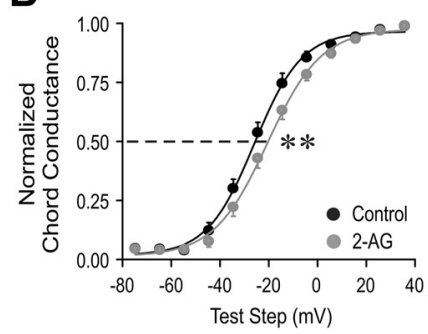

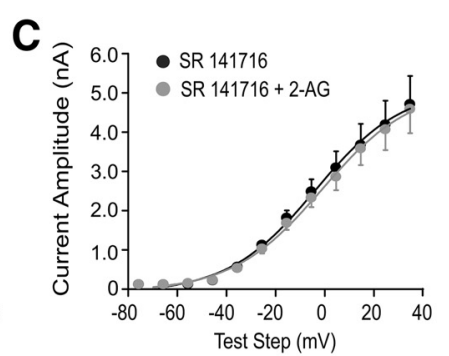

D

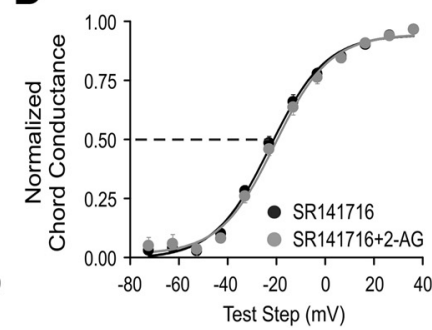

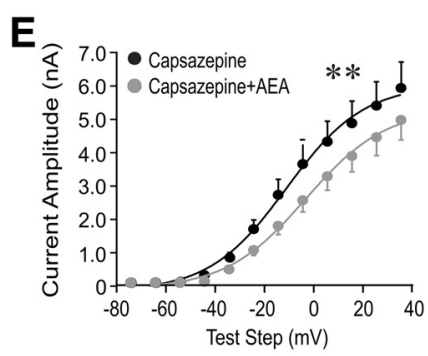

F

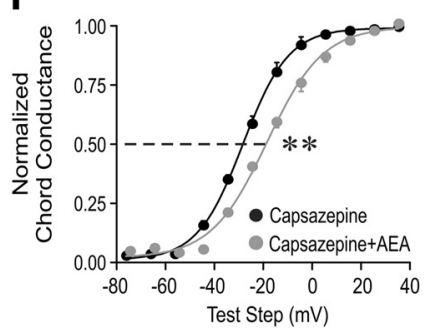

G

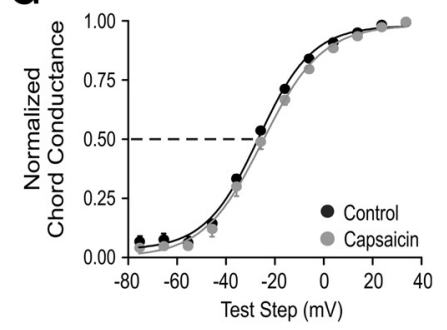

Figure 4. CB1 receptor agonists mimicked the glucocorticoid modulation of $I_{A}$. $A, B$, Bath application of the endocannabinoid $2-A G(1 \mu \mathrm{M})$ elicited a significant decrease in the $I_{A}$ mean peak amplitude $(\boldsymbol{A})$ and a positive shift in the $I_{A}$ activation voltage dependence (normalized chord conductance; $\boldsymbol{B}$ ) in magnocellular neurons from untreated rats. $\boldsymbol{C}, \boldsymbol{D}$, The CB1 receptor inverse agonist SR141716 (rimonabant, $1 \mu \mathrm{M}$ ) blocked the decrease in mean $I_{\mathrm{A}}$ peak amplitude $(\boldsymbol{C})$ and the rightward shift in the chord conductance curve $(\boldsymbol{D})$. $\boldsymbol{E}, \boldsymbol{F}, \mathrm{AEA}$ elicited a decrease in the $I_{A}$ mean peak amplitude $(\boldsymbol{E})$ and a positive shift in the $I_{\mathrm{A}}$ activation voltage dependence (chord conductance; $\boldsymbol{F}$ ) in the presence of the TRPV1 receptor antagonist capsazepine $(1 \mu \mathrm{M})$. $\mathbf{G}$, The TRPV1 agonist capsaicin $(1 \mu \mathrm{M})$ had no effect on the $I_{\mathrm{A}}$ voltage dependence of activation (chord conductance). $* p<0.05 ; * * p<0.01$ with ANOVA in $\boldsymbol{A}, \boldsymbol{C}, \boldsymbol{E}$ and with Student's paired $t$ test in $\boldsymbol{B}, \boldsymbol{D}, \boldsymbol{F}, \mathbf{G}$.

0.05, two-way ANOVA, Bonferroni multiple comparisons test; $n=16$; Fig. $4 A$ ) and a $5 \mathrm{mV}$ positive shift in the $I_{\mathrm{A}}$ half-activation potential $(p<0.01$, Student's paired $t$ test; $n=16$; Fig. $4 B$ ) in PVN magnocellular neurons from untreated rats. This effect of 2-AG on the $I_{\mathrm{A}}$ was blocked by the CB1 receptor inverse agonist SR141716 (1 $\mu \mathrm{M} ; n=$ 6; Fig. $4 C, D$ ).

The other main endocannabinoid, AEA, activates both CB1 receptors and transient receptor potential-vanilloid 1 (TRPV1) receptors (Marinelli et al., 2003; Derbenev et al., 2006), so we blocked TRPV1 receptors with the TRPV1 receptor antagonist capsazepine during AEA application to test AEA modulation of $I_{\mathrm{A}}$ via activation of the CB1 receptor. Preapplication of capsazepine $(1 \mu \mathrm{M}) 10 \mathrm{~min}$ before AEA application had no effect on the $I_{A}$ in magnocellular neurons. AEA $(1 \mu \mathrm{M})$ added to the capsazepine in the bath solution caused a decrease in the $I_{\mathrm{A}}$ peak amplitude $(p<0.01$, two-way ANOVA, Bonferroni multiplecomparisons test; $n=7$; Fig. $4 E$ ) and induced a $10 \mathrm{mV}$ positive shift in the $I_{\mathrm{A}}$ half-activation potential $(p<0.01$, Student's paired $t$ test; $n=7$; Fig. 4F). The TRPV1 agonist capsaicin $(1 \mu \mathrm{M})$ had no effect on the voltage dependence of $I_{A}$ activation (Fig. 4G). These data indicate that CB1 receptor activation with endocannabinoids modulates $I_{A}$ activation in a manner similar to glucocorticoids.

Unlike glucocorticoids, which had no effect on the $I_{A}$ in magnocellular neurons from normally hydrated rats, exogenously applied endocannabinoids induced similar effects on the $I_{A}$ in magnocellular neurons from both normally hydrated and salt-loaded rats. Similar to magnocellular neurons from untreated rats, exogenous application of 2-AG $(1 \mu \mathrm{M})$ to magnocellular neurons from salt-loaded rats caused a significant decrease in the mean peak current amplitude $(p<0.05$, two-way ANOVA, Bon- ferroni multiple comparisons test) and shifted the activation curve of $I_{\mathrm{A}}$ to the right by $3.9 \mathrm{mV}(p<0.05$, Student's paired $t$ test, compared with $5 \mathrm{mV}$ in untreated rats). Exogenous application of the other main endocannabinoid, AEA $(0.5 \mu \mathrm{M})$, also decreased the $I_{\mathrm{A}}$ peak amplitude $(p<0.05$, two-way ANOVA, Bonferroni multiple comparisons test; $n=11$ ), and shifted the $I_{\mathrm{A}}$ half-activation potential positive by $4.1 \mathrm{mV}(p<0.01$, Student's paired $t$ test; $n=11$ ) in PVN magnocellular neurons from saltloaded rats.

We next tested whether the postsynaptic modulation of the $I_{\mathrm{A}}$ by glucocorticoids in magnocellular neuroendocrine cells from salt-loaded rats is dependent on CB1 receptor activation. The CB1 receptor inverse agonists AM251 (1 $\mu \mathrm{M})$ and SR141716 $(1 \mu \mathrm{M})$ by themselves had no effect on $I_{\mathrm{A}}$ amplitude or activation voltage dependence (data not shown), but both AM251 and SR141716 blocked the Dexinduced decrease in $I_{A}$ peak current amplitude (Fig. 5A,C) and the rightward shift in the $I_{A}$ activation curve (Fig. $5 B, D$ ) in MNCs in slices from salt-loaded rats, suggesting the involvement of endocannabinoid in the rapid glucocorticoid modulation of $I_{A}$.

We then tested whether glucocorticoids and endocannabinoids act on the $I_{A}$ through the same signaling pathway or through separate, parallel pathways by testing for occlusion of the glucocorticoid-induced modulation of $I_{\mathrm{A}}$ by previous endocannabinoid exposure. In slices from salt-loaded rats, 2-AG applied alone caused a decrease in the $I_{\mathrm{A}}$ peak current amplitude $(p<0.05$, two-way ANOVA, Bonferroni multiple comparisons test; $n=4$ ) and a $5.5 \mathrm{mV}$ positive shift in the $I_{\mathrm{A}}$ half-activation potential $(p<0.05$, Student's paired $t$ test; $n=4)$. The subsequent application of Dex $(1 \mu \mathrm{M})$, in the presence of 2-AG $(1 \mu \mathrm{M})$, failed to further decrease the peak $I_{A}$ amplitude $(p>0.05$, ANOVA) 
A

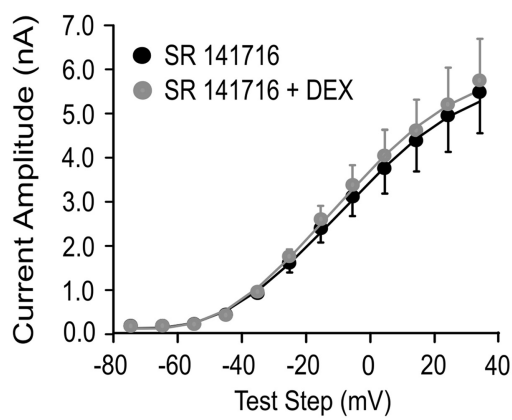

B

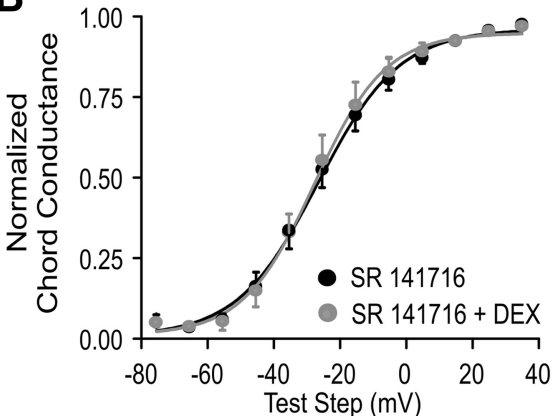

C

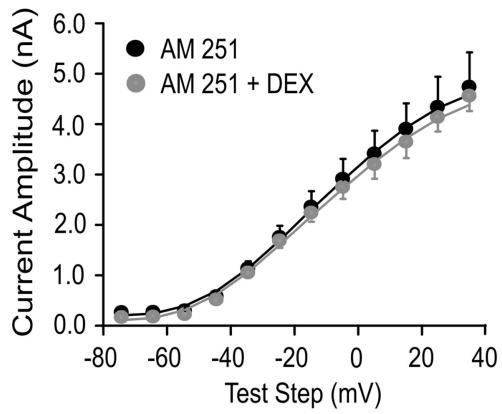

D

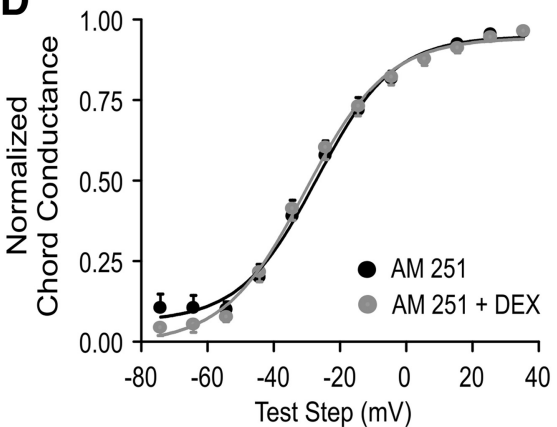

E

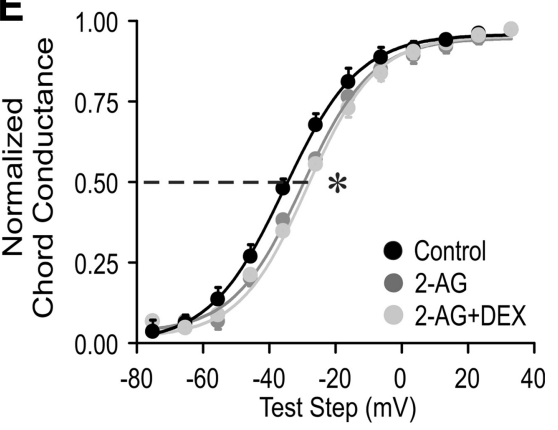

F

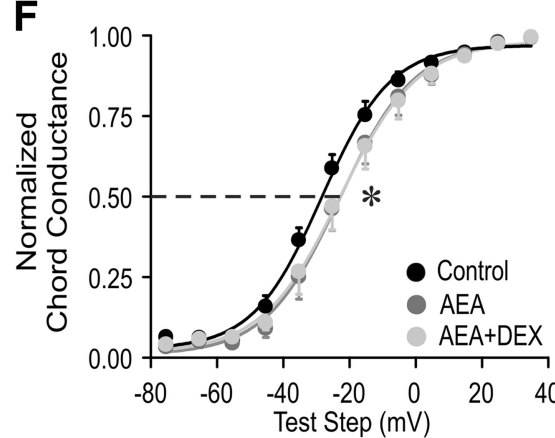

Figure 5. CB1 receptor analogs blocked the glucocorticoid modulation of $I_{\mathrm{A}}$ A, $\boldsymbol{B}$, The CB1 receptor inverse agonist SR141716 $(1 \mu \mathrm{M})$ blocked the decrease in $I_{\mathrm{A}}$ peak amplitude $(\boldsymbol{A})$ and the rightward shift in the voltage dependence of activation (normalized chord conductance; $\boldsymbol{B})$ induced by Dex (1 $\mu \mathrm{M})$ in PVN magnocellular neurons in slices from salt-loaded rats. $\boldsymbol{C}$, $\boldsymbol{D}$, The CB1 receptor inverse agonist AM251 also blocked the Dex-induced decrease in $I_{\mathrm{A}}$ peak amplitude $(\boldsymbol{C})$ and the positive shift in activation voltage dependence (normalized chord conductance; $\boldsymbol{D})$ in PVN magnocellular neurons from salt-loaded rats. $\boldsymbol{E}, \boldsymbol{F}, 2-\mathrm{AG}(1 \mu \mathrm{M} ; \boldsymbol{E})$ and AEA (1 $\mu \mathrm{M} ; \boldsymbol{F})$ caused a positive shift in the $I_{A}$ voltage-dependence curve (normalized chord conductance) from the control value, but subsequent application of Dex $(1 \mu \mathrm{M})$ failed to further shift the curve, suggesting occlusion of the Dex effect by prior CB1 receptor activation. $* p<0.05$ with ANOVA. Student's paired $t$ test.

or to further shift the $I_{\mathrm{A}}$ half-activation potential to the right ( $p>0.05$, Student's paired $t$ test; $n=4$; Fig. $5 E$ ). Similarly, AEA decreased the $I_{\text {A }}$ peak current amplitude $(p<0.05$, two-way ANOVA, Bonferroni multiple comparisons test; $n=4)$ and shifted the $I_{A}$ half-activation potential positive by $5 \mathrm{mV}(p<0.05$, Student's paired $t$ test; $n=4)$. Dex (1 $\mu \mathrm{M})$ failed to decrease the peak current amplitude further $(p>0.05$, ANOVA) or elicit any further rightward shift in the $I_{A}$ half-activation potential in the presence of AEA $(p>$ 0.05 , Student's paired $t$ test; $n=4$; Fig. $5 F$ ).

\section{Possible glial regulation of the glucocorticoid modulation of $I_{A}$}

Chronic dehydration causes a structural change in astrocytic morphology that results in a reduction in the coverage of neurons and synapses by astrocytic processes (Miyata et al., 1994; Theodosis et al., 1995; Hatton, 1997; Tasker et al., 2017) and leads to spillover of synaptic signals to extrasynaptic sites (Boudaba et al., 2003; Fleming et al., 2011). We have found that salt loading causes spillover of endocannabinoid from excitatory synapses to inhibitory synapses, which was mimicked by suppressing glial activity with a gliotoxin (Di et al., 2013). The emergence of rapid glucocorticoid modulation of the $I_{A}$ with dehydration suggests a possible role for glial coverage in the control of autocrine actions of endocannabinoids. To test for a role of astrocyte buffering in the glucocorticoid-endocannabinoid modulation of $I_{\mathrm{A}}$ channels, we used the gliotoxin fluorocitrate to impair astrocyte buffering capability. Fluorocitrate is preferentially taken up by glia and blocks glial metabolic activity, including membrane transport, by inhibiting the citric acid cycle (Clarke, 1991; Gordon et al., 2005). Slices from normally hydrated rats were preincubated for $\sim 2 \mathrm{~h}$ in fluorocitrate $(100 \mu \mathrm{M})$. Dexamethasone $(1 \mu \mathrm{M})$ had a small but significant effect on the $I_{\mathrm{A}}$ in PVN magnocellular neurons in slices from untreated rats exposed to fluorocitrate. Whereas Dex had no effect on the $I_{A}$ peak current amplitude following fluorocitrate treatment $(p>0.05$, ANOVA; $n=8$; Fig. $6 A$ ), it caused a small, but significant, shift to the right in the $I_{\mathrm{A}}$ half-activation potential, by $3.2 \mathrm{mV}(p<$ 0.05 , Student's paired $t$ test; $n=8$; Fig. $6 B$ ). Thus, blocking glial metabolism in slices from untreated rats partially reproduced the effect of in vivo salt loading on the glucocorticoid modulation of the $I_{\mathrm{A}}$.

\section{Discussion}

Glucocorticoids rapidly stimulate the synthesis and dendritic release of endocannabinoids, which act retrogradely to modulate glutamate release from excitatory synaptic terminals onto PVN neuroendocrine cells (Di et al., 2005b, 2009). In addition to their well characterized presynaptic actions, cannabinoids have also been shown to modulate postsynaptic potassium currents (Deadwyler 

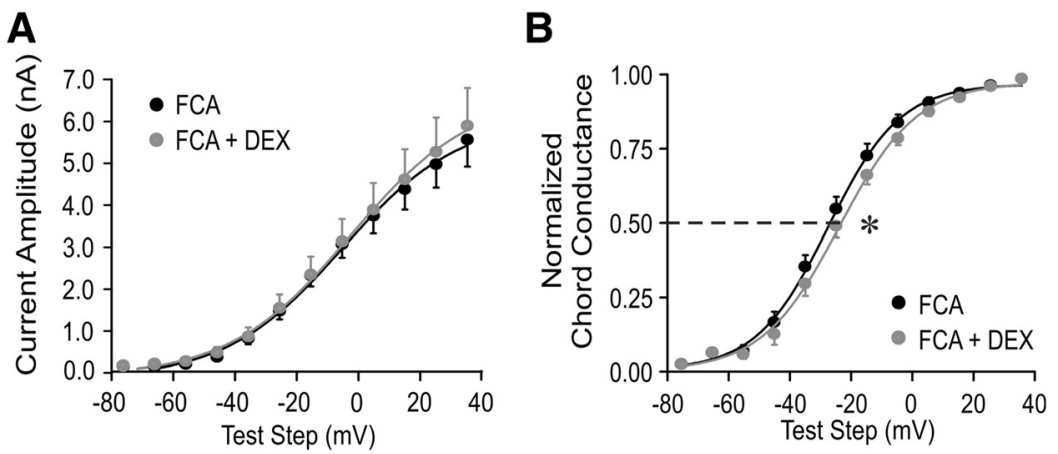

Figure 6. Glucocorticoid modulation of $I_{\mathrm{A}}$ following gliotoxin treatment. Brain slices from untreated rats were preincubated in the gliotoxin fluorocitrate for $\sim 2 \mathrm{~h}$ before recordings. $\boldsymbol{A}$, Following fluorocitrate treatment, Dex had no effect on the $I_{\mathrm{A}}$ mean peak amplitude. $\boldsymbol{B}$, Dex caused a positive shift in the voltage dependence of $I_{\mathrm{A}}$ activation (normalized chord conductance) in fluorocitratetreated slices. $* p<0.05$, ANOVA. Student's paired $t$ test.

et al., 1995; Tang et al., 2005), although, to our knowledge, the regulation of postsynaptic conductance by endogenously released cannabinoids has not been reported. Here, we demonstrate a glucocorticoid-induced suppression of the A-type potassium current in hypothalamic magnocellular neuroendocrine cells that is CB1 receptor dependent, suggesting a postsynaptic autocrine action of endogenously released cannabinoid. The glucocorticoid modulation of $I_{\mathrm{A}}$ occurred rapidly, within minutes of its introduction, and reached saturation within $10 \mathrm{~min}$. The glucocorticoid effect was maintained with the membrane-impermeant Dex-BSA conjugate, indicating that it was mediated by a membrane-associated receptor, and it was not blocked by inhibiting protein synthesis, suggesting a nongenomic mechanism. Therefore, like the rapid glucocorticoid effects on glutamate and GABA neurotransmission in the PVN (Di et al., 2003, 2009), these findings implicate a membrane glucocorticoid receptor in the postsynaptic modulation of $I_{\mathrm{A}}$.

We have performed concentration-response analysis on the rapid Dex-induced endocannabinoid production and retrograde suppression of excitatory synaptic transmission in magnocellular neurons (Di et al., 2005a). In that study, we found that the glucocorticoid-induced endocannabinoid synthesis in magnocellular neurons has a half-effective concentration of $\sim 350 \mathrm{~nm}$ and a saturating concentration near 1 $\mu \mathrm{M}$. We used the near-saturating concentration of $1 \mu \mathrm{M}$ for Dex in this study to approximate the high circulating glucocorticoid levels encountered following stress activation of the hypothalamic-pituitary-adrenal axis. The $1 \mu \mathrm{m}$ concentration of Dex and corticosterone that we used is approximately equivalent to $350-400 \mathrm{ng} / \mathrm{ml}$ concentration of circulating glucocorticoid, which is within physiologic limits. This concentration was ineffective in the magnocellular neurons from untreated rats, which suggested that the effect seen in the magnocellular neurons from salt-loaded rats was not the result of a nonspecific action of the steroid.

We showed previously that glucocorticoids stimulate the synthesis of endocannabinoids in the PVN (MalcherLopes et al., 2006) and that they suppress excitatory synaptic inputs to PVN and SON neurons via the dendritic release and retrograde actions of endocannabinoids (Di et al., 2003, 2005a). Here we demonstrate the endocan- nabinoid dependence of the glucocorticoid modulation of the $I_{\mathrm{A}}$, which suggests that the glucocorticoid-induced release of endocannabinoid also regulates postsynaptic conductance in these cells and is consistent with cannabinoid modulation of $I_{\mathrm{A}}$ in other brain areas (Deadwyler et al., 1995; Tang et al., 2005). In addition to their retrograde actions, therefore, glucocorticoid-induced endocannabinoids are capable of acting in either an autocrine or a paracrine fashion to regulate postsynaptic potassium currents in the PVN.

One possible mechanism of the negative modulation of the $I_{\mathrm{A}}$ by endocannabinoids is that the activation of postsynaptic CB1 receptors triggers a change in the phosphorylation state of the A-type potassium channels. There is a large body of evidence that supports the modulation of $I_{\mathrm{A}}$ by phosphorylation (Covarrubias et al., 1994; Birnbaum et al., 2004; Cai et al., 2005), and CB1 receptors are known to negatively couple via $G_{i}$ to adenylyl cyclase activity, CAMP production, and PKA-dependent protein phosphorylation (Howlett et al., 2004). A decrease in the PKA-dependent phosphorylation of $K_{v}$ channel subunits may result in a decrease in the ability of the voltage sensor of the $I_{\mathrm{A}}$ channel to respond to changes in membrane voltage (Park et al., 2006; Yang et al., 2007). Another possibility is that $\mathrm{CB} 1$ receptor activation leads to the modulation of one or more of the $\mathrm{K}_{\mathrm{v}}$ channel auxiliary proteins, which are well known to regulate the $I_{\mathrm{A}}$ (Covarrubias et al., 1994; Schrader et al., 2009).

The rapid glucocorticoid modulation of the $I_{\mathrm{A}}$ was seen only in magnocellular neurons from rats subjected to chronic salt loading, a treatment known to induce the retraction of astrocytic processes from around magnocellular neurons (Theodosis et al., 1995; Tasker et al., 2017) and result in the synaptic spillover of endocannabinoid from excitatory to inhibitory synapses (Di et al., 2013). The emergent sensitivity to rapid glucocorticoid-induced endocannabinoid modulation of the $I_{A}$ could be caused either by dehydration-induced plasticity of postsynaptic endocannabinoid or glucocorticoid signaling mechanisms or by the loss of glial endocannabinoid buffering due to astrocytic retraction. The neuronal-glial structural plasticity in magnocellular neurons under stimulated conditions (Theodosis et al., 1986; Miyata et al., 1994; Hatton, 1997) 
is accompanied by increasing levels of ambient neurotransmitters, such as glutamate (Oliet et al., 2001; Boudaba et al., 2003) and increasing heterosynaptic and extrasynaptic spillover of neurotransmitters (Piet et al., 2004). We have found that the glutamate synapse-specific effects of glucocorticoid-induced retrograde endocannabinoid actions (Di et al., 2009) are controlled by glial coverage and that, following dehydration-induced glial retraction, endocannabinoid also accesses and activates CB1 receptors on GABA synapses (Di et al., 2013). Our findings here are consistent with glucocorticoid-induced autocrine endocannabinoid actions that are constrained by glial restriction of extracellular endocannabinoid diffusion. That the $I_{\mathrm{A}}$ modulation by exogenously applied cannabinoids was similar in slices from both untreated and salt-loaded rats suggests that the lack of effect of endogenously released endocannabinoid in slices from untreated rats was not due to a change in the sensitivity of endocannabinoid signaling with dehydration. While these findings do not exclude the possibility of a change in the sensitivity to rapid glucocorticoid signaling with salt loading, they may be explained by dehydration-induced glial retraction that expands the extracellular diffusional reach of the endocannabinoid to allow access to postsynaptic CB1 receptors that are normally inaccessible due to astrocytic coverage. However, a role for astrocytes in limiting the glucocorticoid-induced autocrine endocannabinoid actions is still speculative, as it was only partially supported by our recordings in slices in which glial metabolism, and thus endocannabinoid reuptake, was inhibited by the gliotoxin fluorocitrate (Clarke, 1991; Gordon et al., 2005). Thus, fluorocitrate treatment partially recapitulated the dehydration-induced facilitation of glucocorticoid modulation of the $I_{\mathrm{A}}$, as Dex shifted the $I_{\mathrm{A}}$ activation curve but did not suppress the peak $I_{A}$ following fluorocitrate preincubation. Therefore, additional experiments are required to conclusively rule out possible plastic changes in glucocorticoid or endocannabinoid signaling in favor of the loss of astrocytic buffering to explain the emergence of rapid glucocorticoid modulation of the $I_{\mathrm{A}}$ with salt loading.

In magnocellular neurons from chronically dehydrated rats, we observed a glucocorticoid-induced decrease in the peak amplitude and rightward shift in the voltage dependence of activation of the $I_{\mathrm{A}}$. The rightward shift in the activation curve of the $I_{A}$, with no change in the inactivation voltage dependence, means that a greater depolarizing stimulus is required to activate the transient potassium current and that fewer A-type potassium channels are activated with depolarization in the range of the action potential threshold. The lower peak amplitude of the $I_{\mathrm{A}}$ indicates that significantly less current will be activated with depolarization. The glucocorticoid modulation of the $I_{A}$, therefore, should increase the excitability of magnocellular neurons following chronic dehydration. Contrary to our expectations, Dex had no effect on depolarization-induced spiking in neurons from salt-loaded rats. This may be because dehydration itself causes a reduction in the $I_{\mathrm{A}}$ current density (N. Wu and J. G. Tasker, unpublished observation), as well as changes in other voltage-gated conductances (Tanaka et al., 1999; Zhang et al., 2007), which makes it difficult to isolate the impact of glucocorticoid modulation of $I_{A}$ on firing properties.
Glucocorticoid suppression of the $I_{\mathrm{A}}$ in magnocellular neurons during chronic dehydration should enhance the effect of synaptic excitation. Glucocorticoid-induced retrograde endocannabinoid release suppresses presynaptic glutamate release and nitric oxide release enhances presynaptic GABA release onto magnocellular neurons from normally hydrated rats (Di et al., 2005a, 2009). This should negate any excitatory effect of suppressing the $I_{A}$; however, the glucocorticoid facilitation of GABA release is lost during dehydration due to the spillover inhibitory actions of endocannabinoid at GABA synapses (Di et al., 2013). Therefore, the excitation-inhibition balance established by glutamate and GABA release and $I_{\mathrm{A}}$ activation in the dendrites would be tilted toward excitation. This combined with the increased sensitivity to noradrenergic inputs (Di and Tasker, 2004) should enhance or maintain magnocellular neuron activity and neurohypophysial hormone release under conditions of osmotic stress (Hatton, 1997). Collectively, the different effects of glucocorticoids on magnocellular neurons in untreated and chronically dehydrated rats reveal a mechanism for the neuroendocrine system to respond to stress and maintain homeostasis by means of integration of the afferent neural circuit information and circulating hormonal signals.

\section{References}

Birnbaum SG, Varga AW, Yuan LL, Anderson AE, Sweatt JD, Schrader LA (2004) Structure and function of Kv4-family transient potassium channels. Physiol Rev 84:803-833. CrossRef Medline

Boudaba C, Linn DM, Halmos KC, Tasker JG (2003) Increased tonic activation of presynaptic metabotropic glutamate receptors in the rat supraoptic nucleus following chronic dehydration. J Physiol 551:815-823. CrossRef Medline

Cai SQ, Hernandez L, Wang Y, Park KH, Sesti F (2005) MPS-1 is a $\mathrm{K}+$ channel $\beta$-subunit and a serine/threonine kinase. Nat Neurosci 8:1503-1509. CrossRef

Clarke DD (1991) Fluoroacetate and fluorocitrate: mechanism of action. Neurochem Res 16:1055-1058. Medline

Covarrubias M, Wei A, Salkoff L, Vyas TB (1994) Elimination of rapid potassium channel inactivation by phosphorylation of the inactivation gate. Neuron 13:1403-1412. Medline

Deadwyler SA, Hampson RE, Mu J, Whyte A, Childers S (1995) Cannabinoids modulate voltage sensitive potassium A-current in hippocampal neurons via a cAMP-dependent process. J Pharmacol Exp Ther 273:734-743.

Derbenev AV, Monroe MJ, Glatzer NR, Smith BN (2006) Vanilloidmediated heterosynaptic facilitation of inhibitory synaptic input to neurons of the rat dorsal motor nucleus of the vagus. J Neurosci 26:9666-9672. CrossRef Medline

Di Marzo V (2011) Endocannabinoid signaling in the brain: biosynthetic mechanisms in the limelight. Nat Neurosci 14:9-15. CrossRef Medline

Di S, Tasker JG (2004) Dehydration-induced synaptic plasticity in magnocellular neurons of the hypothalamic supraoptic nucleus. Endocrinology 145:5141-5149. CrossRef Medline

Di S, Malcher-Lopes R, Halmos KC, Tasker JG (2003) Nongenomic glucocorticoid inhibition via endocannabinoid release in the hypothalamus: a fast feedback mechanism. J Neurosci 23:4850-4857. Medline

Di S, Malcher-Lopes R, Marcheselli VL, Bazan NG, Tasker JG (2005a) Rapid glucocorticoid-mediated endocannabinoid release and opposing regulation of glutamate and gamma-aminobutyric acid inputs to hypothalamic magnocellular neurons. Endocrinology 146: 4292-4301. 
Di S, Boudaba C, Popescu IR, Weng FJ, Harris C, Marcheselli VL, Bazan NG, Tasker JG (2005b) Activity-dependent release and actions of endocannabinoids in the rat hypothalamic supraoptic nucleus. J Physiol 569:751-760.

Di S, Maxson MM, Franco A, Tasker JG (2009) Glucocorticoids regulate glutamate and GABA synapse-specific retrograde transmission via divergent nongenomic signaling pathways. J Neurosci 29:393-401. CrossRef Medline

Di S, Popescu IR, Tasker JG (2013) Glial control of endocannabinoid heterosynaptic modulation in hypothalamic magnocellular neuroendocrine cells. J Neurosci 33:18331-18342. CrossRef Medline

Ellis LD, Krahe R, Bourque CW, Dunn RJ, Chacron MJ (2007) Muscarinic receptors control frequency tuning through the downregulation of an A-type potassium current. J Neurophysiol 98:15261537. CrossRef

ffrench-Mullen JM (1995) Cortisol inhibition of calcium currents in guinea pig hippocampal CA1 neurons via G-protein-coupled activation of protein kinase C. J Neurosci 15:903-911. Medline

Fleming TM, Scott V, Naskar K, Joe N, Brown CH, Stern JE (2011) State-dependent changes in astrocyte regulation of extrasynaptic NMDA receptor signalling in neurosecretory neurons. J Physiol 589:3929-3941. CrossRef Medline

Gordon GR, Baimoukhametova DV, Hewitt SA, Rajapaksha WR, Fisher TE, Bains JS (2005) Norepinephrine triggers release of glial ATP to increase postsynaptic efficacy. Nat Neurosci 8:1078-1086. CrossRef Medline

Hatton GI (1997) Function-related plasticity in hypothalamus. Annu Rev Neurosci 20:375-397. CrossRef Medline

Hirasawa M, Schwab Y, Natah S, Hillard CJ, Mackie K, Sharkey KA, Pittman QJ (2004) Dendritically released transmitters cooperate via autocrine and retrograde actions to inhibit afferent excitation in rat brain. J Physiol 559:611-624. CrossRef

Howlett AC, Breivogel CS, Childers SR, Deadwyler SA, Hampson RE, Porrino LJ (2004) Cannabinoid physiology and pharmacology: 30 years of progress. Neuropharmacology 47 [Suppl 1]:345-358. CrossRef Medline

Huang MH, So EC, Liu YC, Wu SN (2006) Glucocorticoids stimulate the activity of large-conductance $\mathrm{Ca} 2+$-activated $\mathrm{K}+$ channels in pituitary GH3 and AtT-20 cells via a non-genomic mechanism. Steroids 71:129-140. CrossRef

Luther JA, Tasker JG (2000) Voltage-gated currents distinguish parvocellular from magnocellular neurones in the rat hypothalamic paraventricular nucleus. J Physiol 523:193-209. Medline

Mackie K, Lai Y, Westenbroek R, Mitchell R (1995) Cannabinoids activate an inwardly rectifying potassium conductance and inhibit Q-type calcium currents in AtT20 cells transfected with rat brain cannabinoid receptor. J Neurosci 15:6552-6561. Medline

Malcher-Lopes R, Di S, Marcheselli VS, Weng FJ, Stuart CT, Bazan NG, Tasker JG (2006) Opposing crosstalk between leptin and glucocorticoids rapidly modulates synaptic excitation via endocannabinoid release. J Neurosci 26:6643-6650. CrossRef Medline

Marinelli S, Di Marzo V, Berretta N, Matias I, Maccarrone M, Bernardi G, Mercuri NB (2003) Presynaptic facilitation of glutamatergic synapses to dopaminergic neurons of the rat substantia nigra by endogenous stimulation of vanilloid receptors. J Neurosci 23: 3136-3144. Medline

Miyata S, Hatton GI (2002) Activity-related, dynamic neuron-glial interactions in the hypothalamo-neurohypophysial system. Microsc Res Tech 56:143-157. CrossRef Medline

Miyata S, Nakashima T, Kiyohara T (1994) Structural dynamics of neural plasticity in the supraoptic nucleus of the rat hypothalamus during dehydration and rehydration. Brain Res Bull 34:169-175. Medline

Oliet SH, Piet R, Poulain DA (2001) Control of glutamate clearance and synaptic efficacy by glial coverage of neurons. Science 292: 923-926. CrossRef Medline

Oliet SH, Baimoukhametova DV, Piet R, Bains JS (2007) Retrograde regulation of GABA transmission by the tonic release of oxytocin and endocannabinoids governs postsynaptic firing. J Neurosci 27:1325-1333. CrossRef Medline
Olijslagers JE, de Kloet ER, Elgersma Y, van Woerden GM, Joëls M, Karst $\mathrm{H}$ (2008) Rapid changes in hippocampal CA1 pyramidal cell function via pre- as well as postsynaptic membrane mineralocorticoid receptors. Eur J Neurosci 27:2542-2550. CrossRef Medline

Park KS, Mohapatra DP, Misonou H, Trimmer JS (2006) Graded regulation of the Kv2.1 potassium channel by variable phosphorylation. Science 313:976-979. CrossRef Medline

Piet R, Vargová L, Syková E, Poulain DA, Oliet SH (2004) Physiological contribution of the astrocytic environment of neurons to intersynaptic crosstalk. Proc Natl Acad Sci U S A 101:2151-2155. CrossRef Medline

Roberts EM, Pope GR, Newson MJ, Lolait SJ, O'Carroll AM (2011) The vasopressin $\mathrm{V} 1 \mathrm{~b}$ receptor modulates plasma corticosterone responses to dehydration-induced stress. J Neuroendocrinol 23: 12-19. CrossRef Medline

Schrader LA, Ren Y, Cheng F, Bui D, Sweatt JD, Anderson AE (2009) Kv4.2 is a locus for PKC and ERK/MAPK cross-talk. Biochem J 417:705-715. CrossRef Medline

Schweitzer P (2000) Cannabinoids decrease the $\mathrm{K}^{+} \mathrm{M}$-current in hippocampal CA1 neurons. J Neurosci 20:51-58. Medline

Shah L, Bansal V, Rye PL, Mumtaz N, Taherian A, Fisher TE (2014) Osmotic activation of phospholipase $C$ triggers structural adaptation in osmosensitive rat supraoptic neurons. J Physiol 592:41654175. CrossRef Medline

Tanaka M, Cummins TR, Ishikawa K, Black JA, Ibata Y, Waxman SG (1999) Molecular and functional remodeling of electrogenic membrane of hypothalamic neurons in response to changes in their input. Proc Natl Acad Sci U S A 96:1088-1093. Medline

Tang SL, Tran V, Wagner EJ (2005) Sex differences in the cannabinoid modulation of an A-type $\mathrm{K}^{+}$current in neurons of the mammalian hypothalamus. J Neurophysiol 94:2983-2986. CrossRef Medline

Tasker JG (2006) Rapid glucocorticoid actions in the hypothalamus as a mechanism of homeostatic integration. Obesity (Silver Spring) 14 [Suppl 5]:259S-265S. CrossRef

Tasker JG, Dudek FE (1991) Electrophysiological properties of neurones in the region of the paraventricular nucleus in slices of rat hypothalamus. J Physiol 434:271-293. Medline

Tasker JG, Di S, Boudaba C (2002) Functional synaptic plasticity in hypothalamic magnocellular neurons. Prog Brain Res 139:113119. Medline

Tasker JG, Di S, Malcher-Lopes R (2006) Minireview: rapid glucocorticoid signaling via membrane-associated receptors. Endocrinology 147:5549-5556. CrossRef Medline

Tasker JG, Voisin DL, Armstrong WE (2017) The cell biology of oxytocin and vasopressin cells A2. In: Hormones, brain and behavior, Vol 3 (Pfaff DW, Joëls M, ed), pp 305-336. Amsterdam: Elsevier/Academic.

Theodosis DT, Chapman DB, Montagnese C, Poulain DA, Morris JF (1986) Structural plasticity in the hypothalamic supraoptic nucleus at lactation affects oxytocin-, but not vasopressin-secreting neurones. Neuroscience 17:661-678. CrossRef

Theodosis DT, el Majdoubi M, Gies U, Poulain DA (1995) Physiologically-linked structural plasticity of inhibitory and excitatory synaptic inputs to oxytocin neurons. Adv Exp Med Biol 395:155-171. Medline

Weiss GL, Rainville JR, Zhao Q, Tasker JG (2017) Purity and stability of the membrane-limited glucocorticoid receptor agonist dexamethasone-BSA. Steroids (in press).

Yang JW, Vacher H, Park KS, Clark E, Trimmer JS (2007) Traffickingdependent phosphorylation of Kv1.2 regulates voltage-gated potassium channel cell surface expression. Proc Natl Acad Sci U S A 104:20055-20060. CrossRef Medline

Zaki A, Barrett-Jolley R (2002) Rapid neuromodulation by cortisol in the rat paraventricular nucleus: an in vitro study. $\mathrm{Br} \mathrm{J}$ Pharmacol 137:87-97. CrossRef Medline

Zhang W, Star B, Rajapaksha WR, Fisher TE (2007) Dehydration increases L-type $\mathrm{Ca}(2+)$ current in rat supraoptic neurons. J Physiol 580:181-193. CrossRef Medline 